\title{
WHAT WE KNOW AND WHAT WE OWE
}

\author{
Vanessa Carbonell \\ University of Cincinnati
}

This is the accepted version as submitted. Please cite the publisher's version of record: Vanessa Carbonell, "What We Know and What We Owe", Oxford Studies in Normative Ethics Vol. III, 2013, 235-259, https://global.oup.com/academic/product/oxford-studies-innormative-ethics-9780199685905?lang $=$ en\&cc $=$ us

What to study, where to live, what career to pursue-for those of us with the luxury of making them, these decisions both give our lives meaning and determine what sorts of things we know. Adding that minor in Spanish will render you passably fluent, allowing you to communicate with people you otherwise could not have. Choosing to live in an economically diverse neighborhood might give you knowledge of the cares and concerns of the working poor. Pursuing a career in medicine will likely make you competent to perform certain basic procedures, even if you decide to specialize in psychiatry. But how does what we know bear on what we owe? In one sense, the answer is obvious: knowledge is necessary for certain moral obligations. In learning something new, we sometimes acquire the last necessary element in a set of elements that are jointly sufficient for making us morally required to act. Knowledge thus triggers new obligations, so the choices that shape what we know can also shape what is morally demanded of us. But, as I will show, the existence of these knowledge-based obligations is in substantial tension with the thought that we are free not only to choose the course of our own lives, but also to change our minds and quit, no matter how much knowledge we have already acquired. To resolve this tension, I argue that we need to adopt a relatively demanding understanding of the conditions under which it is permissible to swap one career or life project for another. The result is a compromise that reconciles the moral force of knowledge-based obligations with a basic freedom to choose less-than-morally-optimal life paths.

The paper is divided into four parts. In Part 1, I sketch a puzzle: reasonable principles about freedom are seemingly incompatible with the claim that knowledge can trigger new moral obligations. In Part 2, I argue that knowledge-based obligations are uncontroversial and robust, which suggests that we cannot solve the puzzle by abandoning them. Part 3 introduces a solution to the puzzle: we must narrow the scope of our freedom to "quit at any time". Finally, in Part 4, I examine the timing of knowledge-based obligations, arguing that they do not entail an earlier obligation to embark on educational endeavors, nor do they take full effect until certain formal or informal thresholds have been passed.

\section{THE MOTIVATING PUZZLE}

Moral philosophers have already made great progress in understanding the relationship between knowledge and obligation. There is much excellent work, for example, on cases where people don't know something, and whether this gives them an 
excuse. ${ }^{1}$ I shall focus on the related question of whether what people do know generates additional obligations. And while the existing literature tends to focus on particular beliefs and particular actions, ${ }^{2}$ I shall focus instead on the relationship between large stocks of knowledge or know-how (and large-scale educational endeavors) and patterns of action or behavior. My project is thus concerned not only with the narrow moral question of what to do in a particular circumstance, but the broader question of how to live.

We can see how this broader question arises by examining an apparent tension between three principles that are, I believe, fairly widely (though not universally) accepted by philosophers and nonphilosophers alike. The first is a principle about how we choose our careers or life paths (to the extent that we are able to do so). Call it "Life Path Freedom" (LPF):

(LPF) We are not morally required to pursue the morally best career or life path available to us.

The Life Path Freedom principle is both weak and broad, by design. It is weak insofar as it only says we are not required to pursue the morally best path; it leaves open the possibility that we have very good reason to do so, and that our chosen path can be subject to negative moral evaluation. Further, it says only that we are not required to pursue the best path; it leaves open the possibility that we are required to choose some minimally decent path. It is broad insofar as it concerns both careers and "life paths," where the latter would include many long-term, engrossing, non-remunerative projects, such as having children, pursing a $\mathrm{PhD}$, emigrating from one's country of birth, and pursuing hobbies or volunteer work. $\mathrm{LPF}$ is also neutral about what paths count as "morally best". Different moral theories will give different answers to this question. I use "morally best" rather than, say, "most helpful," in order not to give the impression that the only moral consideration that bears on what we ought to do with our lives is helpfulness (and the absence of harmfulness). ${ }^{3}$

One final note about Life Path Freedom: it is only a principle about what we are (or are not) morally required to do. It says nothing about what it would be good to do according to some other normative standard, such as prudence, well-roundedness, or aesthetic value.

\footnotetext{
1 To give just two examples: In "Culpable Ignorance," Holly Smith considers the case of a doctor who did not know, but should have known, that high concentrations of oxygen can cause blindness in premature babies (1983, p. 543). In "Justified Wrongdoing," Sarah Buss considers the case of an abused teenager who doesn't realize, and perhaps cannot be expected to realize, that not all adults are "potentially dangerous enemies" (1997, p. 354).

2 Accordingly, Smith (1983) considers the moral status of the doctor's particular action-administering excess oxygen - in light of the doctor's particular belief about proper treatments for respiratory distress; Buss (1997) considers the moral status of the teenager's particular action-attacking an adult perceived to be a threat - in light of his particular belief about the dangerousness of adults.

${ }^{3}$ In this respect I am drawing the question more broadly than Sarah Buss does in "Needs (My Own), Projects (Someone Else's), and Reasons" (2007). Buss asks whether she can justify pursuing a minimally helpful career instead of a maximally helpful career. But I'm sure Buss would agree that there are other moral considerations that bear on our choice of career or life path besides helpfulness. That said, the way I am framing the question might complicate her argument, since it leaves open the conceptual possibility that an unhelpful career or life path can be the morally best one. In any case, helpfulness is clearly the most uncontroversial way that an action or life path can be morally good, and so most of my examples involve belping in one way or another.
} 
Nor does it make any claim about how we ought to adjudicate between the requirements of morality and the requirements or recommendations of these other normative standards. It says nothing about whether the moral standard is the ultimate, trumping standard; it makes no claims about whether there is some all-things-considered perspective outside of these standards. In light of all this, we should be modest about how much insight the Life Path Freedom principle brings to the question of how we ought to live. There is more to life than the narrow dictates of morality. But we have to start somewhere, so in this paper I focus on the question of what morality requires of us. ${ }^{4}$

I will not offer a formal argument for LPF. I've drawn it so weakly that I doubt it is especially controversial. ${ }^{5}$ It ought to be accepted by anyone who rejects a kind of "maximizing rationality" in ethics - that is, anyone who rejects the idea that, with respect to a given choice, the morally best option is morally required. It ought to be accepted by anyone who thinks that the demandingness of a moral option can render it nonobligatory. ${ }^{6}$ It ought to be accepted by anyone who thinks that one cannot be morally required to do something that interferes with the kind of non-moral personal projects that are sometimes integral to one's very identity. ${ }^{7}$ And it ought to be accepted by anyone who thinks that, even if there is a highly demanding moral theory in the background, our careers and life paths in particular get a kind of special dispensation, a "pass" from the relentless demand to do the morally best action (if not a pass from the demand to avoid morally bad actions). ${ }^{8}$

In short, I suspect that Life Path Freedom would only be controversial if we accepted something like a strict maximizing consequentialism, with no special exceptions for

\footnotetext{
${ }^{4}$ In this respect, I am focusing on a much narrower question than Susan Wolf in "Moral Saints" (1982). Wolf, too, is interested in how we ought to live, and in what a morally excellent life would look like. However, I take it that Wolf's primary concern is to show that the morally best life would be a life that we find unattractive from an independent, non-moral perspective, which she calls the "point of view of individual perfection" (p. 437). Her view is often thought of us as therefore critical of moral theory. Nevertheless, she would not necessarily have to endorse Life Path Freedom. LPF says that morality doesn't always require us to do the morally best thing. I read Wolf as arguing that, if we lived the morally best life, it would be a life that looks awfully different from what we think the best life, period, should look like. This view has even more force if we are morally required to live the morally best life-that is, if LPF is false.
}

${ }^{5}$ Buss (2007) seems to think that a stronger principle — that we are not even morally required to move from a minimally helpful career to a more helpful career-is widely accepted. If she is correct, then I would imagine that the Life Path Freedom principle_-given that it is significantly weaker-would also enjoy wide support. That said, Buss makes a convincing case that her principle has not been adequately defended by philosophers, and the purpose of her paper is to raise doubt about its truth, or at least its having a "deep justification" (p. 398). Her arguments cannot be ignored, but they presumably apply only in weaker form to this weaker principle.

${ }^{6}$ The idea that a particular moral option is not obligatory because it demands too much is different, of course, from the view that an entire moral theory is implausible because it is too demanding. I think the former alone would be sufficient to entail Life Path Freedom: if some career or life path is morally best, but not required because it demands too much, then Life Path Freedom is true.

7 This would be the kind of "integrity" objection voiced famously by Bernard Williams in "A Critique of Consequentialism” (1973).

8 The idea would be something like Scheffler's (1982) “agent-centered prerogative,” applied especially to careers or life paths. 
"personal projects," no "agent-centered prerogatives," and no distinction between obligation and supererogation. ${ }^{9}$ There is not room here to assess whether such a form of consequentialism is plausible. So I shall remain agnostic on this question, while admitting that I think LPF principle is probably true. ${ }^{10}$

LPF captures an extremely weak version of the thought that we are free to shape the course of our own lives. But does this principle, weak as it is, extend to decisions about whether to discontinue life paths? Allegiance to Life Path Freedom might lead us to accept a somewhat more controversial principle, which we can call Quit at Any Time (QAT).

(QAT) Other things being equal, when pursuing a career or life path, one is morally permitted to quit and change course at any time.

This principle is not strictly entailed by Life Path Freedom. At first it might seem to be: LPF says we don't have to pursue the morally best career, so if continuing in the morally best career is not required, it follows that discontinuing the career is permitted. But this would hold only for the few people already pursuing the morally best career, and even so it is not obvious that a permission to discontinue is a permission to quit at any time. So Quit at Any Time is not a genuine corollary of LPF. Nevertheless, QAT is appealing for the same reason that LPF is appealing: it carves out a sphere of life choices and protects them from at least the most stringent type of moral scrutiny. After all, Life Path Freedom would be a rather pathetic sort of freedom if, once you were established in a given life path, you were stuck

${ }^{9}$ A view like this is defended by Shelly Kagan in The Limits of Morality (1989).

${ }^{10}$ Life Path Freedom might also be controversial to those who think that, at least in some cases, people with rare or exceptional talents (e.g., Michelangelo) are morally required to choose careers or life paths that use their talents. (Thanks to Andrew Schroeder for suggesting this point.) If this is correct, and if those paths or careers are morally best, then LPF is false as stated. Would this be a way to reject LPF without endorsing strict consequentialism? I suspect that consequentialist reasoning underlies many of these judgments. For instance, we might think the reason Michelangelo had an obligation to produce art is that, in doing so, he brought more value to the world than he could have by doing anything else. Nevertheless, there may be nonconsequentialist ways to view this case. Some might think that Michelangelo's obligation, if in fact he has one, is grounded not in the value he produces, but in the idea that the perfection of one's talents is the mark of a virtuous person, and the morally best life path is the one that best exemplifies virtue. Alternatively, one might see his obligation as grounded in an interesting sort of interpersonal relation: talents are unequally and unfairly distributed, and those who are lucky enough to have them owe it to the rest of us not to let them go to waste. We see this line of thinking in the film Good Will Hunting (1997). Ben Affleck's character Chuckie pleads with his best friend, Matt Damon's Will, a self-taught math genius, to use his talents to take a fancy job and move away from the old neighborhood. Chuckie says, "Listen, you got somethin' that none of us have." Irritated, Will says, "Why is it always this? I owe it to myself? What if I don't want to?" Chuckie replies, "Fuck you. You owe it to me. Tomorrow I'm gonna wake up and I'll be fifty and I'll still be [working construction]. And that's all right 'cause I'm gonna make a run at it. But you, you're sittin' on a winning lottery ticket and you're too much of a pussy to cash it in. And that's bullshit 'cause I'd do anything to have what you got! And so would any of these guys. It'd be a fuckin' insult to us if you're still here in twenty years." Chuckie's appeal to the idea of an insult suggests that he is concerned not simply with consequences but with a kind of interpersonal respect. That said, it's clear in the film that this job is not the morally best life path for Will, so Chuckie's stance is compatible with LPF. Moreover, the respect in question seems to trade just as much on Will's special relationship with Chuckie as it does on Will's talent. To make a general nonconsequentialist case for the principle that those with exceptional talents have obligations to use them would require a way of understanding the "insult" or disrespect without appealing to a particular relationship. (Thanks to Ethan Katz for pointing me to this scene.) 
there, on pain of violating a moral requirement.

To see why QAT is plausible, we need to appreciate how weak it is, which requires specifying what is covered by the "other things being equal" qualification. The main purpose of this qualification is to set aside certain special or circumstantial obligations that arise in the course of a career or life path, some of which may be common to all careers or life paths, so as to focus on whether our freedom to choose the course of our own lives includes a freedom to quit and change course irrespective of the comparative moral status of the old and new paths. This is best illustrated by way of an example. Suppose that Jimmy is a certified nurse's aid taking care of people in a nursing home. One day he decides to quit and make a living playing online poker from his basement. Is this change of course morally permissible? Several considerations immediately come to mind. Consider these five:

(1) Jimmy has dependent children. Will poker provide a consistent income to put food on the table?

(2) Unpredictable financial windfalls could tempt Jimmy to make shortsighted decisions, like purchasing a speedboat instead of flood insurance. Will switching careers leave the family worse off overall?

(3) The legal status of profiting from online poker is ambiguous. Is this new career morally forbidden because it might be illegal?

(4) Jimmy makes his decision in the middle of a shift, or even the middle of a procedure. Can he quit if it means the patient in front of him will die?

(5) Even if poker is not wrong, nursing is just a morally better career, for a variety of reasons that vary with your moral theory. Is Jimmy permitted to leave the morally better career for the morally worse one?

The purpose of the "other things being equal" clause is to set aside considerations of type (1)-(4), among many others. Why should we set these aside? Regarding (1), we probably all agree that, if Jimmy has an existing special obligation to put food on the table for his children, and if online poker will not allow him to do so, then he is morally forbidden from quitting nursing and switching to poker. But the fact that Jimmy lacks permission to quit in such a case has nothing to do with the relative moral status of nursing home work compared to online poker; rather, it is grounded in his special obligation to his children. Similarly, regarding (2), if Jimmy knows that poker will cause him to mismanage his finances in a way that ultimately harms the family, then he is probably morally forbidden from switching to poker. But if so, it's because he is forbidden from making choices that he knows will harm his family. This is a general moral restriction that governs all of Jimmy's choices, and is external to his career or life path. The same goes for considerations of type (3): if we are morally forbidden from doing illegal things, and if poker is illegal, then Jimmy is not morally permitted to switch from nursing to poker. But it's not due to a moral prohibition on quitting; it's due to a moral prohibition on illegal careers. We want the Quit at Any Time principle to allow us to hold equal things like the relative legality of the old and new careers, so as to avoid a proliferation of trivial counter-examples, like the fact that you are not morally permitted to quit your nursing job at any time in order to become a gangster. The same goes for (4): without an adequate fleshing out of the "other things being equal" clause, the permission to quit at any time would allow Jimmy to quit, say, after he has disconnected a patient's ventilator tube to quickly clean it, but before he has put it back. It's true that Jimmy can't quit in the middle of the procedure, but it's because other things are not equal: he has a preexisting obligation to finish the procedure or find 
someone who can, independent of any obligation not to quit his job. Perhaps it's a special obligation to this patient, or a contractual obligation to his employer, or just his general obligation as a human being not to harm another human being. Whichever one it is, it's already covered, so we don't need to deny the freedom to quit at any time in order to cover it.

What I'm interested in capturing with the Quit at Any Time principle is the freedom to change one's mind about what to do with one's life without having the decision guided exclusively by moral reasons. QAT says that, assuming other things like legality and special obligations are equal, Jimmy is permitted to switch from nursing to poker, even if poker is morally worse. In other words, QAT directs us to ignore considerations of type (1), (2), (3), and (4), in order to focus on (5). But then it says that considerations of type (5) are not decisive. There is a general moral permission to quit doing what you're doing, and to change to something else, even if doing so is a moral downgrade, so to speak.

Of course, QAT does not say that Jimmy's career change is immune from moral criticism. It does not say that he should ignore moral considerations in making his decision, or that the relative moral status of the careers provides him with no reasons whatsoever. It simply says that, in quitting, he will not have violated a moral requirement-he has a general permission to quit. This permission is presumably grounded in the same basic freedom to shape the course of our own lives that underlies LPF. ${ }^{11}$

To recap, I have suggested that the following two related principles are widely accepted:

Life Path Freedom (LPF) We are not morally required to pursue the morally best career or life path available to us.

Quit at Any Time (QAT) Other things being equal, when pursuing a career or life path, one is morally permitted to quit and change course at any time.

I have also claimed that, while QAT is not logically entailed by LPF, the two principles are based on the same underlying ideas about freedom, and those who believe QAT likely do so for the same reasons that they believe LPF. Now, while one may certainly disagree with either of these principles, there does not seem to be anything especially puzzling about them, alone or taken together. The puzzle comes when we combine QAT with a view about what happens to us, morally speaking, when we acquire certain kinds of knowledge (or certain kinds of skills or experience that are constitutive of knowledge). This view is

${ }^{11}$ I think we not only accept the permission to quit at any time, but in fact glorify it, both in real life and in fiction. For instance, when a JetBlue flight attendant had a particularly stressful flight, he quit his job by grabbing a beer from the beverage cart and sliding down the emergency slide onto the tarmac. People treated him like hero. (Lauren Frayer, "JetBlue Flight Attendant Who Flipped is a Folk Hero," AOL News, August 10, 2010. http://www.aolnews.com/2010/08/10/flight-attendant-who-flipped-becomesfolk-hero/) The movie Office Space (1999) also glorifies quitting one's job, even though the protagonist's new stress-free lifestyle is made possible only by an illegal scheme. Of course, it makes sense to cheer when people quit jobs or projects because they are overworked, oppressed, or simply want to live a less stressful life. But this “Good for you!” attitude sometimes carries over even to cases where people quit non-oppressive and indeed morally admirable projects in order to do nothing, or do something significantly less admirable. 
captured by a principle I'll call the "Burden of Expertise" principle.

Burden of Expertise (BEX) One has certain moral obligations in virtue of possessing certain knowledge, skills, or experience.

I will postpone for the moment discussing what exactly is meant by "in virtue of" in this principle. For now we can understand it as expressing, at a minimum, that if one did not have the knowledge, skills, or experience, one would not have the moral obligations.

The best way to illustrate the Burden of Expertise principle is by looking at some examples. First consider Peggy.

PEGGY. Peggy wrote her doctoral dissertation in anthropology on the power relations between rival tribes in Waziristan, the volatile region between Pakistan and Afghanistan. Now happily employed as a professor at a small liberal arts college and writing about other things, Peggy gets approached by officials at the State Department. They ask her to take a yearlong sabbatical and come advise them on peace-making and terrorism-prevention strategies in the area. No one in the world has exactly the same expertise Peggy has, though there are others with other kinds of relevant knowledge. Though Peggy would prefer teaching, she feels obligated to accept the offer and agrees to the one-year post.

It seems that Peggy's obligation to take the post - if she is indeed so obligated-is conditioned on her expertise and the fact very few people have comparable expertise. If she did not have this particular expertise, or if there were a long line of comparable experts ready and willing to take the post, she would not be so obligated. Surely other moral factors - such as beneficence and civic duty-also contribute to the obligation, but a good explanation of why she ought to accept it would refer to her technical knowledge.

Now consider the case of Roz.

ROZ. Roz is a pediatric cardiac surgeon who specializes in fixing a rare congenital heart defect in young children. She has trained for years to do this work: college, medical school, residency, and fellowship all prepared her to be the surgeon she is today. At age 39, she is the most talented surgeon in her geographical area, which means that she gets sent the most critical cases. It's fair to say that, without her, the care of these children would be compromised, and some might die while being transported to distant hospitals to be treated by the few other experts. Roz likes her work and isn't burnt out, but she also has another passion: French literature. She is considering leaving medicine, at least for several years, to pursue a $\mathrm{PhD}$ in French literature and write a book.

Is Roz morally required to stay at her job rather than pursue her passion for French literature? Suppose she can't do both, and suppose that, since she is not burnt out or depressed, abandoning her plan to study French literature would not render her so disappointed as to compromise her abilities as a surgeon. I propose that Roz is morally required to stay in medicine, in virtue of her expertise. If she left her job, it would be fitting for those in her community not only to lament the state of affairs - to say, "what a shame," or "think of those poor sick kids" — but also to blame her, to be angry with her, to feel wronged. These are reactive attitudes characteristically associated with the failure to meet a 
moral obligation. We can imagine her coworkers shaking their heads to each other, saying that her decision was "selfish" or "frivolous," even when they would not normally accuse a scholar of French literature_-one who had pursued that path since college_of being selfish or frivolous. And if Roz follows through with her move, we can imagine her feeling guilty while sitting in French class, thinking of the kids she could have saved. This would not be the same guilt that anyone might feel at not having donated more money to UNICEF to prevent childhood diseases in the developing world. Nor would it be a guilt associated with breaking promises to particular children already under her care, since she is thinking of hypothetical, future patients. Rather, it would be guilt about a more personal misgiving: guilt about not using the technical knowledge and experience that she possesses. It would be the guilt of not carrying the burden of her expertise.

Judgments about these cases may differ, and I am not offering the cases as an argument for the Burden of Expertise principle. Nevertheless, I think the cases can make vivid how the principle captures a strain in our common sense thinking. Granted, we may have mixed feelings. Perhaps we go back and forth between thinking that Roz would be blameworthy for making the switch and thinking, as Oprah might put it, that Roz is free to live her best life, and that she doesn't have to carry all those sick kids on her shoulders. But even ambivalence on this matter is enough to raise interesting questions. To the extent that we are even tempted to believe both that Roz has a moral burden associated with her technical knowledge and that we are generally free to quit and change course at any time, we are faced with a puzzle.

The puzzle is this: if it is true that (other things being equal) we can quit at any time (QAT), then how can it be the case that, once far enough along in a career or life path to have acquired some knowledge (or skills or experience), we can be morally obligated to take certain actions in virtue of that knowledge (BEX)? After all, QAT says we can quit at any time-presumably including now! Instead of fulfilling this new moral obligation, this "burden" of our expertise, why not just quit?

While the puzzle can be generated by QAT and BEX alone, Life Path Freedom is lurking in the background. I have argued that a commitment to QAT is grounded in the same views about freedom that motivate LPF. And without QAT, LPF loses some of its force. After all, without the freedom to quit at any time, the permission to choose a lessthan-morally-best path only goes so far: if you have already chosen the morally best career, you are stuck! So in order to resolve the puzzle, we need to either weaken our commitment to knowledge-based obligations, or weaken our commitment to quitting at any time, which would mean scaling back our freedom to shape the course of our lives.

Of course, the Peggy and Roz examples might show that BEX is present in our commonsense moral thinking, but they do not show that BEX is true. So in the next section I try to spell out exactly why BEX is true. Then, in Section 3, I argue for a compromise that preserves the Burden of Expertise at the expense of weakening Quit at Any Time. We may need to admit that you cannot quit at just any time.

\section{KNOWLEDGE-BASED OBLIGATIONS}

How can the mere possession or acquisition of knowledge create moral obligations? After all, knowledge may generally be necessary for moral obligation, but it is never by itself sufficient. We may agree that, in most or all cases, if you do not know how to $\phi$, you are not obligated to $\phi$. To think this is just to be committed to obligated implies knows how, a 
species of the obligated implies can principle, ${ }^{12}$ itself a weaker and even less controversial cousin of ought implies can. And we should be committed to obligated implies knows how, at least for most cases, because to say that someone is morally obligated to do something is to say quite a lot. ${ }^{13}$ It is to say that she has decisive reason to do it, that we can legitimately demand it of her, that we can hold her accountable if she fails to do it, that she could demand the same of us if we were similarly situated, and that it would be fitting for herand for us - to feel and express morally-laden reactive attitudes if she failed to do it. So it would seem just downright unfair, not to mention pointless, for someone to be morally obligated to do something she simply cannot do because she does not know how.

But it is obviously not the case that, in general, if you do know how to $\phi$, then you are obligated to $\phi$. (Know how to steal a car? It doesn't follow that you must. Knows how implies obligated is a nonstarter.) Instead, new knowledge creates new obligations only in circumstances where it adds to existing obligation-grounding reasons. So the principle we're after is something like this: knows how, and has otherwise nearly decisive moral reason to, implies obligated. Another way to put it is this: knowledge "triggers" obligation when it provides one of the necessary and jointly sufficient conditions for obligation-specifically, when it is either the last (temporally) of the conditions to obtain, or when it is the condition that sets a given agent apart from some comparison class. I will hereafter use "create" and "trigger" interchangeably; both are really just metaphors for a set of facts or reasons coming to obtain.

Recall the Burden of Expertise principle (BEX): One has certain moral obligations in virtue of possessing certain knowledge, skills, or experience. For BEX to be true, there simply need to be cases where knowledge is added to existing moral reasons that are otherwise nearly decisive, or where knowledge sets one agent apart from others. Surely such cases abound. For example, suppose a man collapses on the train platform and is dying while waiting for the paramedics. As the sole bystander, I would be obligated to save his life, but I do not know how. (Fortunately, the paramedics arrive just in time.) Coincidentally, a CPR course is offered at my workplace that day, and I take it. On my return commute, shockingly, another man collapses on the train platform. No one else on the platform has the relevant knowledge, but now I do. A knowledge-based obligation has been triggered. My training triggers the obligation both by being the last necessary condition to obtain and by being the necessary condition that distinguishes me from the other bystanders.

Now, at this point the existence of knowledge-based obligations may seem so uncontroversial as to be not worth discussing: of course the person who knows CPR now

\footnotetext{
12 Not knowing how is not the same thing as not being able; it is one species of not being able. We are interested in cases where it is precisely the lack of knowledge that entails the lack of ability. I cannot lift an elephant because my muscles are not up to the task. I cannot make a round square because it is metaphysically impossible. But I cannot speak Spanish because I don't know how. This distinction is important if knowledge plays a distinctive role in our lives or identities.
}

${ }^{13}$ Obligated implies knows how may not always be true. Perhaps it is possible to be able to do something despite not knowing how. I think this question turns on tricky conceptual issues about knowledge and ability that I cannot explore here. An additional question is whether the relevant factor is what a person knows or rather what it would be reasonable for her to believe in light of her evidence. In "The Moral Clout of Reasonable Belief' (2011), Holly Smith makes a case for ignorance being an excuse even when the ignorance itself was inexcusable. In other words, she argues that it's what we actually believe, not what it would be reasonable for us to believe, that is relevant to how we should be morally assessed for whatever actions we take in light of our beliefs. 
bears a new moral burden that other bystanders do not. And yet these knowledge-based obligations are noteworthy for several reasons. First, they illustrate that what is morally demanded of a given agent is remarkably plastic; the set of moral obligations she faces can change rapidly in the face of contingent, nonmoral considerations like whether she happens to have just seen a documentary on global warming or dogfighting. ${ }^{14}$ Also, what is morally obligatory can differ dramatically from one agent to the next. While this may seem obvious in light of the wide diversity of circumstances in which people find themselves, it takes on a provocative tone when we focus specifically on differences in knowledge: we do not always have control over how much or how little we know, and yet those who know more, owe more.

Another noteworthy feature of knowledge-based obligations is their relation to an agent's identity. Of course, knowledge is not the only thing that can trigger obligations. But we are often responsible for our knowledge and skills-responsible for choosing to pursue them, for succeeding in acquiring them, and for tirelessly working to perfect them. In this way they are part of us, and sometimes reflective of our character, in a way that other obligation-triggering abilities may not be. For example, if someone has fallen in a hole and needs help, a bystander may be obligated to help in virtue of being the only bystander with long enough (but not exceptionally long) arms. This is a case where the fact that the bystander can help in this particular way triggers an obligation that is defeated for other bystanders with shorter arms. But being able to help make peace in Waziristan because of your scholarly expertise and being able to lift someone out of a hole because of the length of your arms are two very different things. Knowledge-based obligations can be tied to our identities, and triggered by features about ourselves that we can take credit for, in ways that set them apart. ${ }^{15}$

Now, the CPR example was simple and narrowly circumscribed. What are even more interesting are large-scale bodies of knowledge, long-term educational endeavors, and major decisions about careers and life paths-decisions like those faced by Peggy and Roz. What makes these cases more interesting is that they involve a kind of knowledge or expertise that takes years to acquire. Generally speaking, the more time and effort you devote to a knowledge-producing project (whether it be formal schooling or getting to know the needs of a community), the more likely it is that your knowledge is substantial, highly specialized (i.e., narrow), and rare. The more substantial, specialized, and rare your knowledge is, the greater the number and urgency of the demands it may trigger. ${ }^{16}$ Of

\footnotetext{
14 Perhaps this should come as no surprise. After all, moral obligation need not be anything magical, eternal, or unchanging. Rather, it is arguably a contingent and contextual social phenomenon, a system of demands we are justified in making upon one another in light of an underlying authority we have as mutually responsible agents in a community. This authority might be "second-personal" in nature, as Stephen Darwall argues in The Second-Person Standpoint (2006). Whatever the nature of the authority and the corresponding obligation at the conceptual level, I take it that the content of the obligations could take a variety of forms, including consequentialist.

15 Of course, knowledge may not be the only ability that is special in this way. If saving the person who fell in the hole requires not long arms but strong arms, and I have strong arms because I am an Olympic athlete, then perhaps my strength is tied to my identity in interesting ways despite not being a kind of knowledge. Even this case, though, would count as knowledge if brute strength is considered a skill and skill is considered a kind of knowledge.
}

16 There are exceptions, of course. Insubstantial, unspecialized, or relatively common knowledge can trigger obligations in moments of extreme demand, like natural disasters. And rarity is always relative to 
course, the longer it takes you to acquire the knowledge or skill, and the more substantial, specialized, or rare it is, the more likely it is to be tied up with your identity and your values. So you're not simply faced with a bunch of bland, bureaucratic prescriptions: because I know x, I must do y. Rather, you're faced with the broad moral implications of the kind of agent you have chosen to mould yourself into. ${ }^{17}$ This brings us back to the puzzle of the previous section. Does this new moral landscape, filled with knowledge-based moral obligations, conflict with the freedom to Quit at Any Time?

Quit at Any Time (QAT) Other things being equal, when pursuing a career or life path, one is morally permitted to quit and change course at any time.

Burden of Expertise (BEX) One has certain moral obligations in virtue of possessing certain knowledge, skills, or experience.

If my argument has succeeded in demonstrating the existence of knowledge-based moral obligations, then the Burden of Expertise principle is true. If BEX is true, then it is hard to see how QAT could also be true. Let's assume that Peggy's knowledge of Waziristan triggers an obligation to work for the State Department, and that Roz's skill in performing surgery on kids' hearts triggers an obligation to stay at her job. ${ }^{18}$ If Peggy and Roz are morally obligated to do these things, how could it be true that they are morally permitted to quit or change course and pursue some other life path? Quitting would seem to be an all-tooconvenient way to escape their moral obligations.

\section{QUITTING WITHOUT BLAME}

\footnotetext{
context-language skills, for example, can be highly valuable in one community and relatively useless in another. It is also worth emphasizing that many careers or life paths involve a type of knowledge that is substantial, specialized, and rare (relative to context), without requiring advanced degrees or being traditionally accorded a high status in society. After Hurricane Sandy hit New York, there was a shortage of qualified licensed electricians who were needed to inspect and repair the wiring in homes whose basements had flooded. One electrician interviewed by National Public Radio noted his sixteen-hour workdays and claimed that, though he misses his wife, turning down requests would mean leaving people without heat at the beginning of winter. It sounds like he felt bound by a knowledge-based obligation. (Joel Rose, “N.Y. Electrician Shortage Hampers Sandy Recovery” National Public Radio 11/29/12.)

${ }_{17}$ Of course, knowledge is just one part of what makes an agent who she is. I don't mean to suggest it is any more morally relevant than, say, the emotional constitution one has developed over time or the web of relationships one has built. Indeed I mean to construe knowledge as broadly as possible, so as to potentially include certain emotional capacities and relationships.

${ }_{18}$ Must Peggy and Roz be uniquely qualified for the jobs in order for the obligation to be triggered? I think not. It is enough that they are qualified, and that no one else has stepped up (i.e., they are uniquely willing). Perhaps others are also obligated, but are shirking their duties. This doesn't seem to weaken the force of the obligations for Peggy and Roz. This is a tricky issue though, and I can't do justice to it here. Suffice it to say that issues of unique qualification and noncompliance need to be sorted out for obligation in general. Knowledge-based obligations do not raise special problems here.
} 
The most straightforward solution to this puzzle is to modify the Quit at Any Time principle. Although freedom to quit is an important component of our general freedom to shape the course of our own lives, and although it is very tempting to think that we can (other things being equal) quit at any time and for any reason, we may be too quick to let ourselves off the moral hook. Once a knowledge-based moral obligation is triggered, as with any moral obligation, we must fulfill it on pain of being blameworthy.

Of course, knowledge-based moral obligations are, like all moral obligations, defeasible. A knowledge-based obligation might be defeated if one cannot discharge it while reasonably maintaining one's mental health, financial security, or familial relationships. For example, suppose Peggy's work with the state department exposes her to repeated death threats that, though unlikely to amount to anything, will cause her significant psychological distress, to the point where she cannot sleep at night. This would surely be a defeater if we thought it would compromise Peggy's ability to do a good jobin such a case, there would be a violation of obligated implies can. But it may even be a defeater if we thought that Peggy could continue to do a good job, albeit while suffering a kind of psychological torture. In this case the obligation would be defeated simply because it asks too much. This can all take place from within the "moral point of view"; we need not reach any conclusions about how to weigh Peggy's moral obligations against, for example, the counsels of prudence.

A knowledge-based obligation might also be defeated if it conflicts with some other, stronger obligation, even if the knowledge-based obligation was triggered first. For example, suppose Eve is an astronaut with special training in how to fix part of the International Space Station. She might have a knowledge-based obligation to follow through with a planned mission, even if she decides before departure that she'd rather be an ice skater. But if her only child then becomes gravely ill, her obligation as a mother to be at her child's bedside could surely override and thus defeat her obligation to go on the mission. She cannot do both, and she must be with her child. So she cannot go on the mission. So the obligation to go on the mission would violate obligated implies can. And so the obligation is defeated. ${ }^{19}$

After accounting for defeaters, many knowledge-based obligations remain. So we need a modification of the Quit at Any Time principle, one that makes it consistent with the existence and strength of these obligations. I propose the following principle, which we can call "Quitting Without Blame" (QWB):

(QWB) Once knowledge-based obligations associated with one's career or life path have been triggered, one is morally permitted to quit or change course only if one fulfills one's existing or immediate particular obligations and then either (1) switches to a life path that will allow one to make an approximately equally significant moral impact or (2) ensures that the knowledge-based obligations are taken over by a comparable substitute.

\footnotetext{
${ }^{19}$ Rather than calling these circumstances "defeaters" that "nullify" the obligation, some will insist that the obligation exists, but the agent is not blameworthy for failing to fulfill it, because she has an excuse. But if obligations are demands that we legitimately make of one another, I don't see how it could be legitimate for us to demand both that Eve the astronaut fix the space station and that she stay home with her sick child.

Nevertheless, it doesn't matter for my argument which framework we use. In the language of excuses, I would simply say that: needing to be at her child's bedside excuses Eve from her obligation to fix the space station, but wanting to be an ice skater does not.
} 
This may initially seem like a rather high bar for quitting. In a case like Roz's, where her obligation to continue performing surgery seems not to be defeated in any of the usual ways, she would need to meet one of the two conditions in QWB in order change course blamelessly. After performing the surgeries in her existing queue, she would need to either find a suitable permanent replacement for herself, or switch to a life path that allowed her to make an approximately equal moral impact. Would writing a book on French literature that a few dozen people might read count as making an equal moral impact? Probably not, though a wide variety of other things might.

Of course, this is asking a lot of Roz. If she studied French literature from the beginning and had never gone to medical school, we wouldn't be bothering her-after all, we believe in Life Path Freedom. But it would also be asking a lot to say that Roz is morally required to remain as a surgeon when there are other paths she'd like to pursue. What the Quitting Without Blame principle allows her to do is to transfer the burden of her expertise to some other life path.

The two conditions of QWB are intended to preserve what is most compelling about Quit at Any Time while doing justice to the moral force of knowledge-based obligations. What is most compelling about Quit at Any Time? First, the quitting part: it allows us not just to change course, but even to slow down, stop, or downgrade what might be a morally admirable life path, without having violated some general obligation to "stay the course". ${ }^{20}$ Quitting Without Blame preserves this by allowing even those with significant knowledge-based obligations to make a moral downgrade, provided that they satisfy the second condition and find a substitute. In this sense, those who bear a "burden of expertise" are just as free to quit as anyone else, albeit in less dramatic fashion: rather than walking out on a whim, they must transfer their burden responsibly. The second compelling element of Quit at Any Time is the any time part. The idea here is that part of our freedom to shape our lives is essentially temporal. If you have to stick around for three years to train your replacement, your life path is held hostage to an old decision-you are less free. In Quitting Without Blame, those with knowledge-based obligations can quit at any time - possibly the same day! - if they discharge their existing particular obligations and then satisfy the first condition by switching to a morally comparable career.

Of course, QWB still imposes a thicker level of moral bureaucracy, as it were, than QAT did. And QWB does not allow an agent both to quit immediately without finding a replacement and to make a moral downgrade. So the agent in a sense has to choose just one of the two compelling kinds of freedom that the original principle provided. This compromise is necessary in order to preserve the Burden of Expertise. ${ }^{21}$ Indeed, QWB reminds us that agents need to take their knowledge-based obligations as least as seriously as they take their other moral obligations, including the obligations set aside by the "other things being equal" clause of Quit at Any Time. We said earlier that you cannot quit nursing in order to become a poker player if doing so means violating a special obligation to take

${ }^{20}$ Recall, however, the "other things being equal" clause in QAT: we may have preexisting, special, contractual, or other ancillary obligations that render quitting impermissible.

${ }^{21} \mathrm{QWB}$ is offered as a proposal, and unfortunately there is not space to defend it against various alternative proposals. Specifically, one might legitimately worry that QWB favors preserving the strength of BEX when one could instead propose a principle that weakens BEX in order to preserve the intuitions behind QAT. While I have tried to show that BEX is uncontroversial, it does depend on a fairly rigid conception of the strength and scope of our moral obligations, and it does privilege the notion of obligation over weaker forms of moral recommendation. I intend to explore these issues further in future work. 
care of your children. What we can now see is that you also cannot quit nursing to become a poker player if your nursing expertise has triggered a robust set of knowledge-based obligations; just like the obligations to your children, you must discharge or transfer these responsibly before it is permissible to quit.

\section{TIMING, THRESHOLDS, AND TRIGGERING}

I have argued that there are serious moral implications to the knowledge we acquire in the course of our lives. Not only does knowledge frequently trigger new obligations, but these obligations are especially stubborn. Perhaps without even realizing it, we may find ourselves in a situation where what we have learned actually constrains our freedom, or at least our freedom to shape our lives without the weight of moral criticism and blame. This moral landscape might seem rather oppressive, but just how oppressive it is depends on answers to certain questions about the timing of knowledge-based obligations. In this section I address two such questions: (1) Do prospective knowledgebased obligations carry forward into the present, generating an obligation to learn? (2) At exactly what point during the knowledge-acquisition process do knowledge-based obligations become triggered?

\subsection{Prospective Knowledge-Based Obligations}

If knowledge triggers obligations, and if I am interested in being a good person, it would seem that I should acquire as much knowledge as possible! But even if I am only aiming to be a minimally decent person, we might wonder whether it is permissible for me to forgo various opportunities for formal or informal education, especially if I know that such education would bring moral burdens. ${ }^{22}$ Of course, there are various moral and prudential arguments for why education is good, whether for its own stake or as an instrument to other valuable ends. But the question here is whether, specifically, the existence of hypothetical future knowledge-based obligations renders a person obligated to take certain educational paths. This could be seen as a version of the question of when ignorance is culpable, but on a much grander scale. It is one thing to look backwards at a moral failure resulting from ignorance and ask, should the agent have known better? It is quite another to look into the uncertain future, where various types of knowledge might trigger obligations, but only in combination with the right contingent moral and nonmoral background conditions, and ask, what must one learn?

Suppose, for example, that Esther, a law student in Minnesota, is contemplating taking classes in a Hmong dialect. ${ }^{23}$ There are tens of thousands of Hmong refugees living

\footnotetext{
22 Elsewhere, I have argued that one particular way of increasing our obligations is by learning about reallife moral saints. They show us what it's like to take on great sacrifices, alleviating a kind of ignorance we otherwise had, which had been acting as a defeater of certain obligations (Carbonell, 2012).

23 Since my examples involve doctors, lawyers, teachers, etc., one might naturally question whether these knowledge-based obligations are simply "role obligations" in disguise. A role obligation as "a moral requirement, which attaches to an institutional role, whose content is fixed by the function of the role, and whose normative force flows from the role" (Hardimon 1994, 334). Certainly the two are related. Often one comes to occupy a certain role in virtue of having certain knowledge. Nevertheless, not every role
} 
nearby, and Esther believes that, if she gains some fluency in the language, she will be obligated on account of her rare expertise to volunteer in her law school's legal clinic helping Hmong clients who have nowhere else to turn. Given this prospective knowledgebased obligation, is she obligated to sign up for the class? I think we should be skeptical that she is, for at least two reasons. First, the background conditions grounding the prospective obligation could change during the year it takes to study the language. Apple or Google might come out with an artificially intelligent translation tool so effective that it renders human interpreters unnecessary. Or Esther might acquire other, stronger moral obligations that displace this new one. These may be remote possibilities. But the point is that there is a high bar for obligation: we may think Esther ought to learn the dialect, but this cannot be the decisive ought of obligation, given how much uncertainty is involved.

Second, there are an infinite number of hypothetical knowledge-based obligations. There are simply too many of them for it to make any sense that they could generate decisive reasons for action in the present without being unreasonably demanding. Learning the Hmong dialect is just one of countless things Esther could learn, and helping the Hmong in the law clinic is just one of countless morally worthy things she could do if she had the right knowledge, skill, or expertise. Even if we limited the set of potential activities to just things Esther has some antecedent interest in learning, or to skills that are desperately needed in her area, there is a further worry: choices like whether to learn a new language or take on a long-term volunteer endeavor are precisely the sorts of decisions that are meant to be covered by Life Path Freedom. Recall that LPF said we are not morally required to choose the morally best life path. Now, it is compatible with LPF that Esther has good reason (albeit not an obligation) to work at the law clinic. But this reason presumably is grounded in the needs of the refugees, and not anything having to do with Esther's knowledge or skill, which she does not yet possess. It seems that not only is there not an obligation here, but what moral reasons there may be are grounded in considerations independent of the prospective knowledge-based obligation. The knowledge-based obligation itself_-or rather, the fact that it would obtain in the hypothetical situation in which Esther had the knowledge-cannot entail an earlier obligation to learn Hmong.

\subsection{Thresholds}

If knowledge-based obligations don't take effect before the knowledge is acquired, then when exactly do they take effect? Often there is no simple fact of the matter about whether and when a given agent knows $p$ or knows how to $\phi$. Learning is typically a process, not an event. When we say that an agent knows how to speak Spanish, or knows how to fix the Space Station, or can perform a certain surgery, or is an expert on Waziristan, we are making a claim that is inherently vague. Must Roz's surgeries all be successful? Must Eve know how to fix every part of the Space Station? If not, then we need to know at what

\footnotetext{
obligation reduces to or presupposes a knowledge-based obligation - think of the role obligations associated with being a daughter, which may exist regardless of any particular knowledge. And not every knowledge-based obligation reduces to or presupposes a role obligation-think of a knowledgeable retired teacher stranded in an airport, who finds herself obligated on account of her knowledge to teach the fellow passengers a lesson (in survival skills, or critical thinking, or whatever) despite not occupying the role of "teacher" with respect to them. There is more to say here, of course, but to do the issue justice will require another paper.
} 
point in their training Roz and Eve became good enough to trigger knowledge-based obligations. This question is important, because once these obligations are triggered, I have argued that you need to meet certain conditions in order to quit or change course without blame (QWB). But what if you want to quit or change course during your training-can you then invoke Quit at any Time (QAT)?

What is at stake here is moral obligation, and I have been understanding moral obligation to be in part a social phenomenon in which we hold each other, as equals, mutually accountable for behaving in accordance with reasons that are shared and public. ${ }^{24}$ Accordingly, I think it makes most sense to see knowledge-based obligations as being triggered by certain formal and publicly accepted thresholds. These thresholds include milestones, degrees, tests, or credentials within a field that are considered to be either indicative of, or in fact constitutive of, mastery of a given body of knowledge or skill. Paradigm examples of such thresholds would be completing the CPR course, passing the Bar Exam, graduating from medical school, becoming a certified dog trainer, etc. Because we all know the purpose of a CPR course, and we trust those who design it to ensure that passing it is a reliable indication of competence, it is reasonable for us to expect that the one bystander among us who has passed the course take on responsibility for intervening in an emergency.

However, while these formal thresholds are sufficient for the triggering of knowledge-based obligations, it is worth asking whether they are always necessary. After all, there is a degree of arbitrariness in setting the thresholds, and they are often intended to define the scope of professional (or even legal) roles and responsibilities, not moral responsibilities. Someone who fails the Bar Exam by one point cannot practice law, but she may know just as much about how to research the case of a wrongfully accused prisoner as someone who passed with flying colors. Since knowledge-based obligations are supposed to be triggered by the acquisition of the relevant knowledge itself, we should admit that in some cases this knowledge will be acquired before, or in the absence of, the passing of a public threshold. Thus partially-trained agents can incur knowledge-based obligations.

The problem, though, is that as soon as knowledge-based obligations are triggered, a person's freedom to shape her own life is constrained, because Quitting Without Blame requires her to find a substitute or a morally comparable alternative path. If you learn enough in the first semester of nursing school to be bound by QWB, what good is Life Path Freedom? Our choices about what paths to follow would be ominous indeed if we were stuck after just one semester. Given that knowledge is so crucial to developing projects of moral value, it makes sense to protect the knowledge-acquisition process itself from the reach of those obligations, lest no one ever achieve real expertise. In order to avoid a system of obligations that is self-defeating in the long term, it makes sense to say that partially-trained agents can only incur knowledge-based obligations if (1) no fully-trained agents are available, and (2) discharging these obligations does not interfere with the completion of the training itself. For example, a $3^{\text {rd }}$-year medical student may do a monthlong internship in a rural area and find that her nascent skills are in such dire need that she bears a "burden of partial expertise". She may incur a knowledge-based obligation to work extra hours while she's there, or to go beyond her minimal job duties, or return on her next vacation. But we would not want to say that this burden requires her to quit medical

${ }^{24}$ See above, note 14 . For a more detailed discussion of why questions of moral obligation require appeal to mutually intelligible values or reasons, see Carbonell (2012). 
school and move to the rural area immediately, as this would undermine her acquisition of a level of expertise that might enable her to perform even more urgently needed moral duties in the future.

Of course, many important kinds of knowledge are acquired informally, without thresholds of any kind, arbitrary or otherwise. For example, one who lives in a struggling neighborhood may, over time, acquire knowledge about the needs and concerns of its residents. This knowledge could ultimately trigger obligations - to vote a certain way in a city council election, to participate in a rally, etc. In the absence of any well-defined threshold, we will have to say that these obligations get triggered individually, that is, whenever it becomes the case that there is something of moral value that one can do, and that one has otherwise nearly decisive moral reason to do, but that one could not do until one knew how - and now one does (more or less) know how. If these individual actions culminate in a large project-say, playing a leadership role in the neighborhood association - then one might have to meet the conditions of Quitting Without Blame if one wants to quit or change course. Such judgments are highly contextual, of course. Nevertheless, the general framework I've provided can apply not only to well-defined careers and formal courses of education, but also to the vast body of equally important non-codified knowledge that enables people to take on projects of moral value.

\section{CONCLUSION: FREEDOM AND MORAL DEMANDS}

The view I've put forward in this paper tries to reconcile our freedom to choose our own career or life path without moral blame (LPF), our corresponding freedom to quit and change course (QAT/QWB), and the fact that many of our life choices bring with them burdensome moral obligations (BEX). The compromise I've articulated is, admittedly, quite demanding. One might worry, though, that the view is worse than unreasonably demanding: that it is unsatisfactory on its own terms. In replacing Quit at Any Time with the more demanding Quitting Without Blame, have we not violated Life Path Freedom? QWB says that you must trade your life path for one that is approximately morally equal; you cannot downgrade without finding a moral understudy for yourself, which is likely to be more difficult as your level of expertise increases. In this way, QWB might be thought to punish excellence by constraining the freedom of precisely those agents who are already bearing large moral burdens.

In fact, QWB does not conflict with Life Path Freedom. LPF only says that you are free to choose something other than the morally best path. QWB does not require you to choose the morally best path-though if you are that rare person who is already living the morally best life, QWB says that you can only change to one that is tied for best. To be sure, QWB significantly constrains one's freedom; but LPF is compatible with this reduced freedom. LPF permits you to choose a less-than-best path, but it doesn't say you can choose any path whatsoever. Perhaps the real worry here is that Life Path Freedom was too weak to begin with: maybe we do think you should be able to choose any path whatsoever. But the more freedom we build into LPF, the more it will conflict with the Burden of Expertise principle, which I have shown is straightforwardly true.

Some people simply will not be able to discharge all of their knowledge-based obligations while maintaining complete freedom to choose the course and shape of their lives, especially after they cross thresholds of competence. The problem is not that QWB is too restrictive, but that knowledge_-combined with the right background conditionsmakes possible such burdensome moral obligations in the first place. Thus the view leaves 
us with a version of the familiar problem of morality's demandingness. I cannot solve this problem. But if gaining expert knowledge puts you in a position to contribute to morally beneficial projects, to fight injustice, or to lessen suffering, then the simple fact that you ought to continue doing so seems like not such a bad problem to have. ${ }^{25}$

\section{REFERENCES}

Sarah Buss. 1997. “Justified Wrongdoing.” Nous 31(3): 337-369.

Sarah Buss. 2007. "Needs (Someone Else's), Projects (My Own), and Reasons.” Journal of Philosophy. 103(8): 373-402.

Vanessa Carbonell. 2012. "The Ratcheting-Up Effect." Pacific Philosophical Quarterly. 93(2): 228-254.

Stephen Darwall. 2006. The Second-Person Standpoint. Cambridge, MA: Harvard University Press.

Lauren Frayer. 2010. "JetBlue Flight Attendant Who Flipped is a Folk Hero," AOL News, August 10, 2010. URL: http://www.aolnews.com/2010/08/10/flight-attendant-whoflipped-becomes-folk-hero/. Accessed December 1, 2012.

Michael O. Hardimon. 1994. "Role Obligations." Journal of Philosophy. 91(7): 333-363.

Mike Judge (Director). 1999. Office Space. DVD. $20^{\text {th }}$ Century Fox.

Shelly Kagan. 1989. The Limits of Morality. New York: Oxford University Press.

Joel Rose. "N.Y. Electrician Shortage Hampers Sandy Recovery." National Public Radio, November 29, 2012. URL: http://www.npr.org/2012/11/29/166139923/n-y-electricianshortage-hampers-sandy-recovery. Accessed December 14, 2012.

Samuel Scheffler. 1982. The Rejection of Consequentialism. New York: Oxford University Press.

Holly Smith. 1983. “Culpable Ignorance.” The Philosophical Review 92(4): 543-571.

25 I am grateful to Marie Jayasekera, Amanda Roth, and Dustin Locke for their generous comments on early fragments of this paper. I would also like to thank the audience at the Third Annual Arizona Workshop on Normative Ethics for helpful discussion. With apologies for those whose names I have forgotten, let me especially mention Teresa Blankmeyer Burke, Cheshire Calhoun, Don Fallis, Daniel Groll, Thomas Hurka, Howard Nye, Douglas Portmore, and Holly Smith. Finally, I would like to thank two referees for Oxford University Press, one of whom revealed himself to be Andrew Schroeder, for valuable feedback which improved the paper considerably. Work on this paper was supported by a Center Fellowship at the University of Cincinnati's Charles Phelps Taft Research Center. 
Holly Smith. 2011. "The Moral Clout of Reasonable Belief." In Timmons, ed., Oxford Studies in Normative Ethics, Vol 1. New York: Oxford University Press.

Gus Van Sant (Director). 1997. Good Will Hunting. DVD. Miramax Studios.

Bernard Williams. 1973. "A Critique of Utilitarianism." In Smart and Williams, Utilitarianism: For and Against. Cambridge: Cambridge University Press.

Susan Wolf. 1982. “Moral Saints.” Journal of Philosophy 79(8): 419-439. 